EESTI NSV TEADUSTE AKADEEMIA TOIMETISED. GEOLOOGIA

ИЗВЕСТИЯ АКАДЕМИИ НАУК ЭСТОНСКОИ ССР. 1 ऽОЛОГИЯ PROCEEDINGS OF THE ACADEMY OF SCIENCES OF THE ESTONIAN SSR. GEOLOGY

$1985,34,3$

УдК [551.794:551.312]

Тийу КОФФ, Я.-М. ПУННИНГ

\title{
О НЕКОТОРЫХ ЗАКОНОМЕРНОСТЯХ ВОЗДУШНОГО ПЕРЕНОСА ПЫЛЬЦЫ
}

Изучение закономерностей воздушного переноса спор и пыльцы, их распределения в атмосфере и на земной поверхности представляет интерес для различных ученых. В последние годы этими исследованиями, например, занимаются и медики, так как установлено, что причиной многих аллергических заболеваний является пыльца некоторых ветроопыляемых растений (Палинология в медицине, 1973). Особенно большое значение имеет спорово-пыльцевой метод в геологии. Применение спорово-пыльцевого метода в стратиграфических и палеогеографических исследованиях основывается на сходстве палино- и фитоценозов. Ключевой вопрос здесь - выявление закономерностей формирования спорово-пыльцевых спектров в зависимости от продуктивности пыльцы отдельных видов растений, воздушного и водного переноса спор и пыльцы, условий их сохранения и т.д.

Кроме интерпретации спорово-пыльцевых диаграмм, большое значение для изучения циркуляции воздушных масс и механизма вымывания микронных и субмикронных частиц из атмосферы имеет выявление закономерностей воздушного транспорта и распределения спор и пыльцы в атмосфере. Учитывая, что пыльца некоторых древесных растений (сосны, ольхи, а также вяза) встречается в кернах современных ледников Земли Франца-Иосифа и Шпицбергена (Сурова, 1982) на расстоянии нескольких тысяч километров от ареала их распространения, можно говорить о глобальном фоне распределения пыльцы. Вариации количества пыльцы можно отчасти объяснить изменениями в преобладающих циркуляционных механизмах, а также количеством осадков, что, по Т. Г. Суровой $(1982)$, является определяющим при вымывании пыльцы из атмосферы. Таким образом, изучение распределения пыльцы в атмосферных осадках может служить ценным дополнением к данным по изучению атмосферного переноса микроэлементов или субмикронных аэрозольных частиц.

С целью выявления некоторых закономерностей распределения пыльцы воздушным путем в весенне-летнем сезоне 1982-1983 гг. на ряде станций Управления гидрометеорологической службы Эстонской ССР (УГМС) (рис. 1) выставили стеклянные пластины $(9 \times 12$ см), покрытые липким слоем глицериново-желатиновой эмульсии. Пластины ставили в горизонтальном положении на зысоте около 50 см от земной поверхности в открытой местности не менее чрм в 50 м от больших деревьев. Сменяли пластины сотрудники станции УГМС через каждые 5-7 дней.

Дополнительные исследования проводились также на территории опытной станции Тоома и Нигулаского государственного заповедника (рис. 1), где пластины ставили в разных ландшафтных условиях.

До и после экспонирования пластины хранили в плотно закрытых камерах, в которых их и переносили в лабораторию. Обрабатывали 


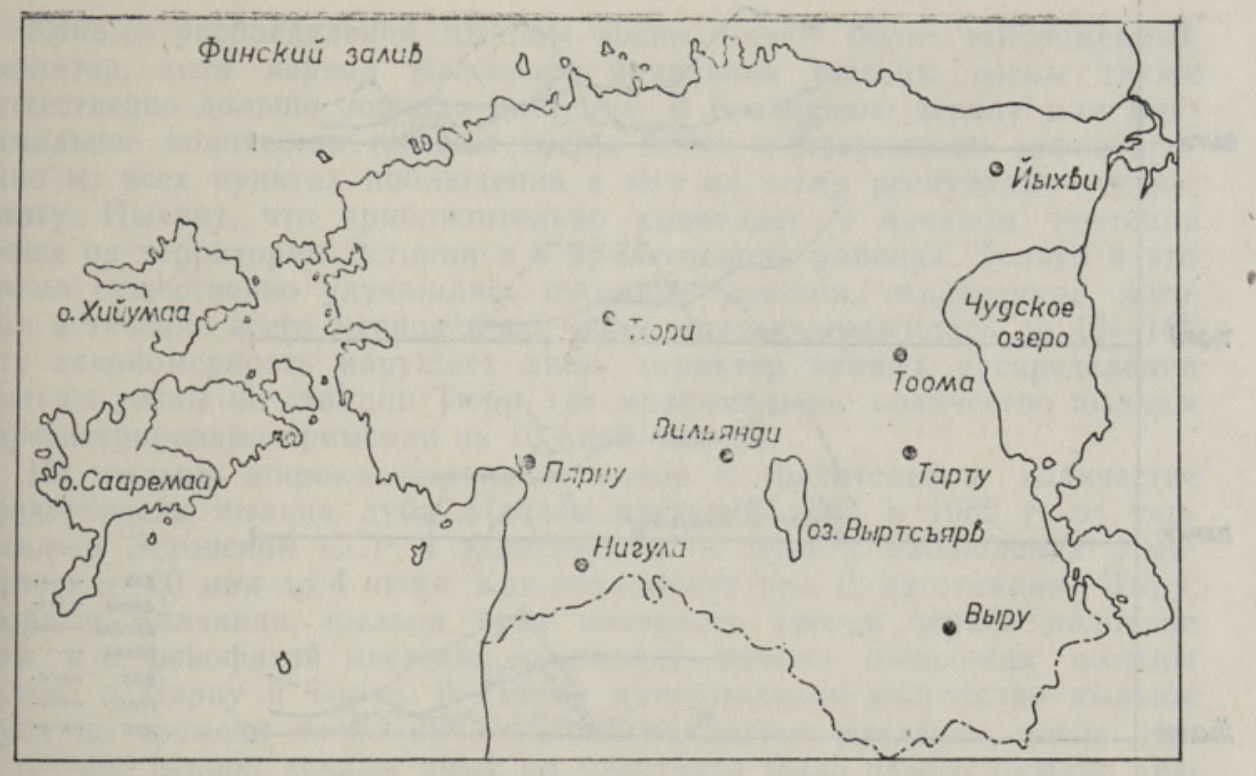

Рис. 1. Пункты экспонирования пластин для улавливания пыльцы.

пластины и подсчитывали пыльцевые зерна следующим образом. На экспонированные пластины наносили $1-2$ капли концентрированной серной кислоты, затем препарат покрывали стеклом и под микроскопом при помощи счетной доски подсчитывали количество пыльцевых зерен отдельных видов растений на площади $1 \mathrm{~cm}^{2}$. Обработка серной кислотой не только не нарушала структуру пыльцевых зерен, но даже способствовала выявлению особенностей их морфологического строения. Такая обработка позволяла также избавиться от некоторых мелких частиц, затрудняющих видовые определения.

На первом этапе исследования пыльцу подсчитывали на 10 выбранных участках площадью $1 \mathrm{~cm}^{2}$, но как показал опыт, пыльца распределялась весьма равномерно, и для получения надежных данных достаточно было просмотреть не более $3-4$ участков.

Основными определяющими климат факторами на территории Эстонской ССР являются интенсивное действие циклона в северной части Атлантического океана и непосредственное окружение Балтийского моря. Мягкие морские условия перемежаются с резкими проникновениями холодных масс воздуха с севера и северо-востока. По этой причине, несмотря на относительно небольшую площадь, природные условия в разных частях республики различны, что выявляется и во временных различиях фенологических явлений. Например, фенофазы развития растительности в Южной Эстонии на 7-10 дней опережают соответствующие фенофазы в Северной Эстонии.

На рис. 2 приведены изменения временно́го распределения коли-

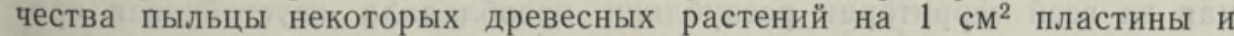
начало их массового цветения. Привлекает внимание тот факт, что массовое появление пыльцы березы начинается в большинстве случаев до начала цветения берез вблизи соответствующих пунктов наблюдения. Полные циклы присутствия пыльцы березы наблюдались только в Пярну и Вильянди. Здесь кривые распределения пыльцы резко различаются. В Вильянди четко выделяется период максимального распространения пыльцы березы, составляющий не более двух недель. Примерно тот же вид имеют соответствующие кривые, полученные для Москвы (Губанкова, 1973). В Пярну максимальное появление пыльцы 


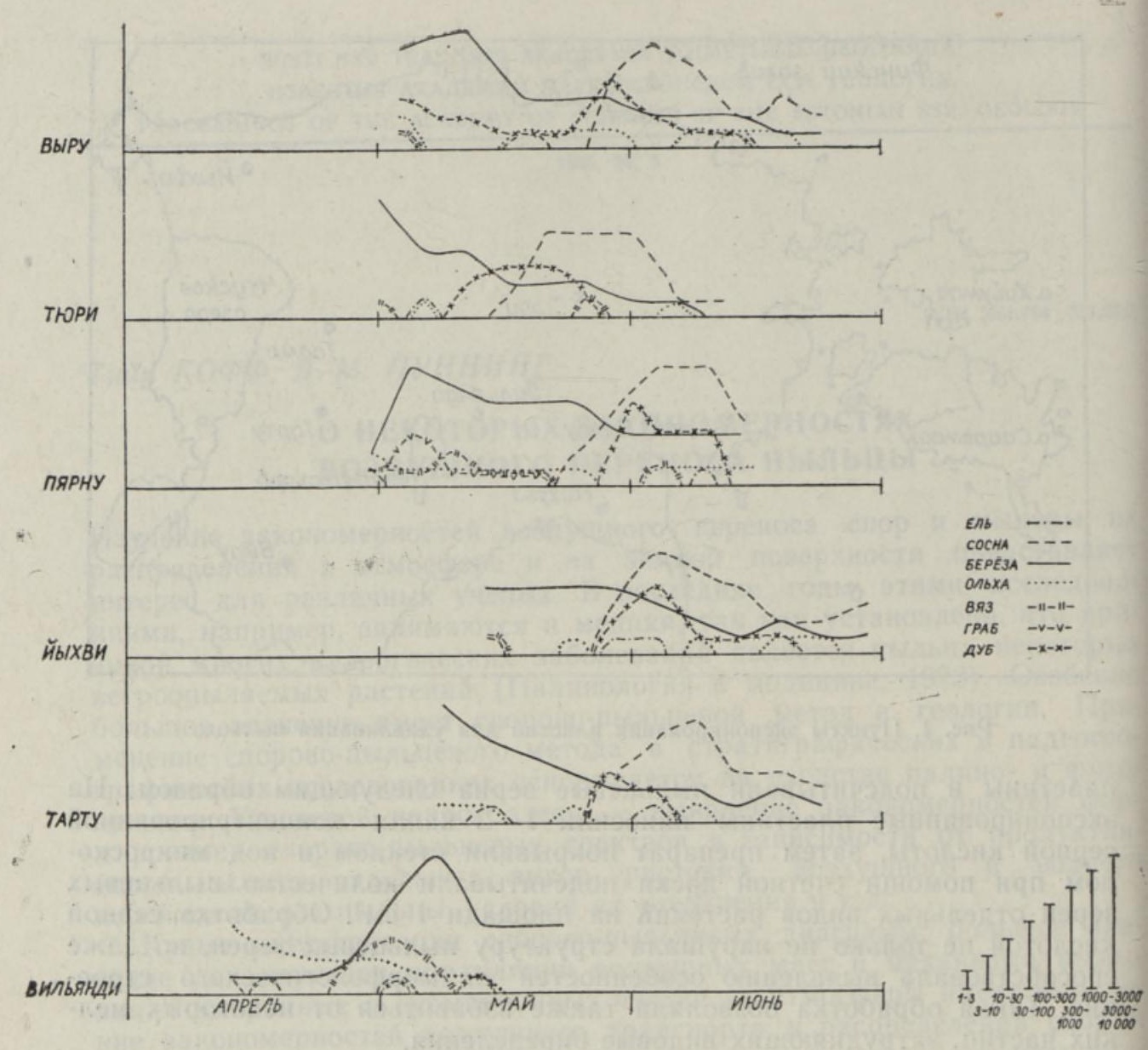

Рис. 2. Динамнка содержания пыльцевых зерен на пластинах, установленных на разных пунктах экспонирования территории Әстонской ССР. Шкала количества пыльцевых зерен - в правой нижней части рисунка.

березы начинается на несколько дней раньше, в первые дни мая, но после короткого максимума, еще до конца мая, происходит осаждение пыльцы березы в довольно значительном количестве. Небольшое количество пыльцы березы отмечено до конца периода наблюдений во всех пунктах исследования, что говорит о постоянном ее привносе. В пользу такого заключения свидетельствует и массовое появление пыльцы березы до начала цветения. Фенологические наблюдения показывают, что цветение березы в 1982 г. началось в конце первой декады мая. По метеорологическим данным, в конце апреля и в начале мая на всей территории республики преобладала неустойчивая прохладная погода, туманы и слабые ветры, средняя температура была ниже нормы на $2-4{ }^{\circ} \mathrm{C}$. Известно, что интенсивность цветения и его начало коррелируют со средними температурами воздуха (Bringfelt и др., 1982). Поэтому можно предположить, что по всей республике пыльники березы начали раскрываться около 5-6 мая, когда повсеместно среднесуточная температура повысилась до $8-12^{\circ}$ при максимальной температуре воздуха $21-24^{\circ} \mathrm{C}$. Это значит, что значительная часть пыльцы березы или привнесена из более южных районов, или переотложена с земной поверхности, еще не покрытой травой. 
Кривые распределения пыльцы сосны имеют более закономерный характер, хотя период массового появления пыльцы сосны также существенно дольше периода цветения. В последнюю декаду мая макснмальное количество пыльцы сосны почти одновременно зафиксировано во всех пунктах наблюдения с юга на север республики (Выру, Тарту, Иыхви), что приблизительно совпадает с началом цветения сосны на территории Эстонии и в прилегающих районах. Только в это время существенно улучшились погодные условия, температура, которая в течение всего месяца была ниже нормы, повысилась до $12-16^{\circ}$. Эту закономерность нарушает лишь характер кривых распределения пыльцы сосны на станции Тюри, где максимальное количество пыльцы зарегистрировано примерно на 10 дней раньше.

Из пыльцы широколиственных видов в значительном количестве представлена пыльца дуба. Начало цветения дуба в 1982 г. на территории Әстонской ССР в зависимости от пункта наблюдения отмечалось от 20 мая до 4 июня. Қак показывает рис. 2, на станциях Выру, Тюри и Вильянди, пыльца дуба появилась уже в первой половине мая, и с фенофазой цветения совпадает начало появления пыльцы только в Пярну и Тарту. В Пярну максимальное количество пыльцы дуба по времени точно приходилось на период цветения, после чего в течение первой декады июня на пластинах было зафиксировано зна-

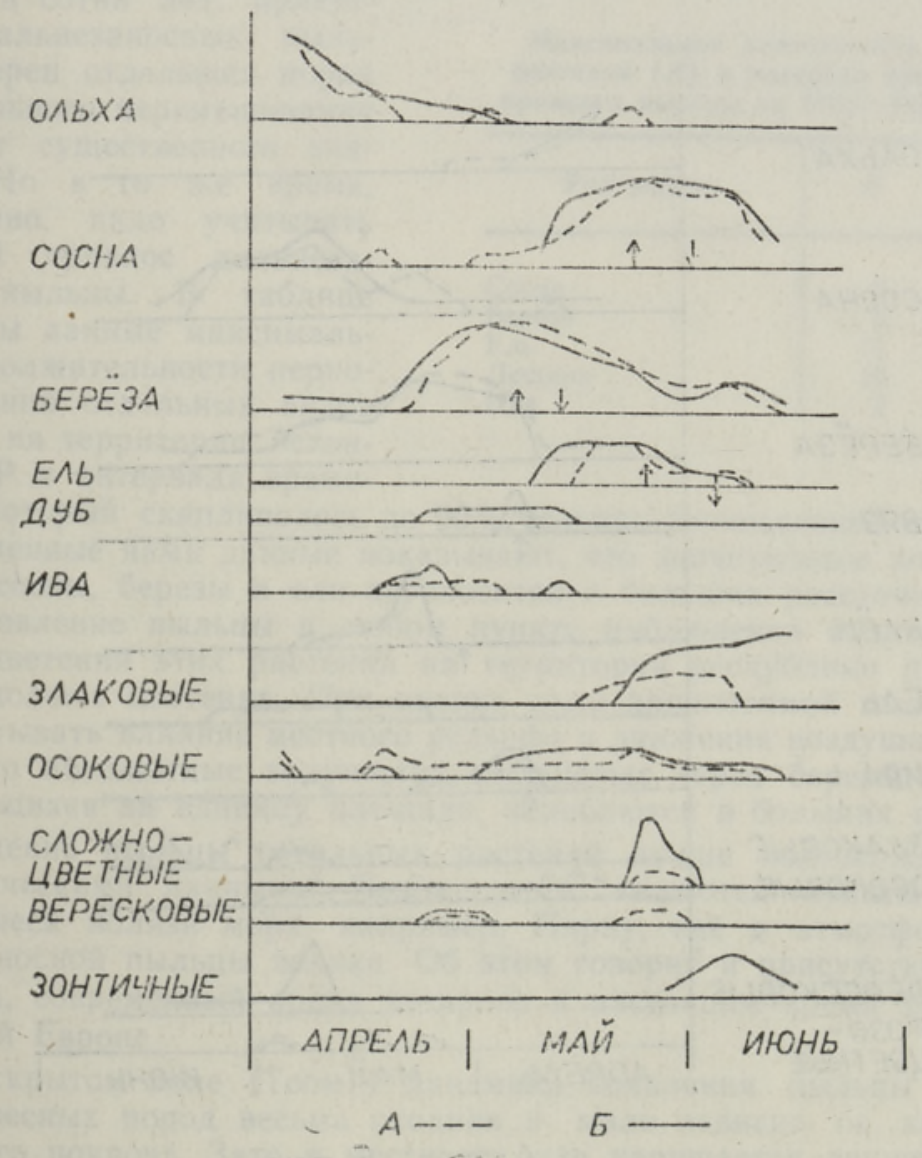

Рис. 3. Динамика содержания пыльцевых зерен на пластинах, установленных на верховом болоте $(A)$ и на поле $(D)$. оптной станции Тоома. Стрелками обозначены начало и конец цветения. Шкала количества пыльцевых зерен на рис. 2. 
чительное кंоличество пыльцы. В то же время Пярну - единственная станция, где встречается пыльца граба.

Для изучения влияния местных ландшафтных условий на распределение пыльцы в апреле-июне 1983 г. пластины ставили на территории опытной станции Тоома и в Нигула (рис. 1). На территории опытной станции Тоома пластины помещали на верховом болоте и на возвышенном месте, примерно в 1 км от края болота. Большие лесные массивы в окрестности, в радиусе 1 км, отсутствуют. Полученные данные (рис. 3) показывают, что нет различий в распределении пыльцы древесных пород, в некоторой мере различается лишь ход распределения пыльцы трав. Следовательно, на открытой местности происходит хорошее осреднение пыльцы в атмосфере и отсутствует ощутимое влияние ветрового переосаждения.

Влияние местного растительного покрова на состав осаждающейся пыльцы изучалось ранее в Эстонии П. Томсоном (Thomson, 1937). Мы проводили исследования на территории болот Нигула. В восточной части болота расположена цепь минеральных островков, состав растительности на которых резко отличается от растительности вокруг болота. Там доминируют хвойно-березовые леса, на островках - широколиственные. Мы проводили наблюдения в двух точках - непосредственно на восточной окраине одного из островков и, примерно в $300 \mathrm{~m}$ восточнее его, на верховом болоте. Как видно на рис. 4, здесь доми-

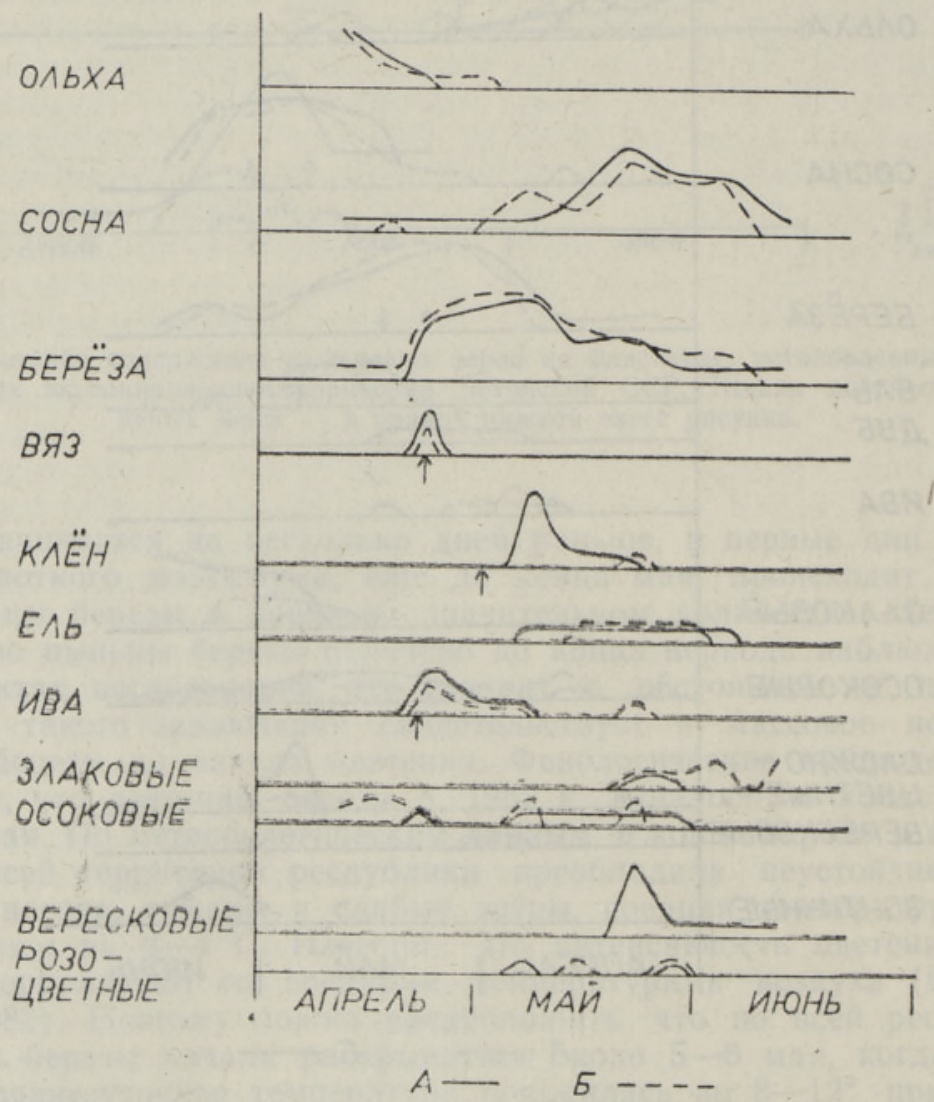

Рис. 4. Динамика содержания пыльцевых зерен на пластинах, установленных на островке $(A)$ и в 300 м от островка $($ ( $)$ в Нигула. Стрелками обозначены начало и конец цветения. Шкала количества пыльцевых зерен на рис. 2. 
нирует пыльца сосны, березы и лещины, причем состав пыльцы ощутимо не различается в зависимости от места экспонирования. Пыльца этих видов, широко распространенных вокруг болот, привнесена издали и их концентрация в атмосфере хорошо усреднена. Судя по длительности периода привноса пыльцы, ясно, что источником пыльцы этих пород является большая территория. В то же время пыльца вяза и клена, растущих на островке, имеет узкое распространение. Особенно это касается клена, количество пыльцы которого на расстоянии $300 \mathrm{M}$ от деревьев резко уменьшается. Пыльца травянистых пород переносится на очень близкие расстояния и ее видовой состав хорошо отражает растительный покров вблизи выставленной пластины.

Фенологические наблюдения в 1982-1983 гг. показывают, что период цветения березы на территории Эстонии составляет около 6 дней, причем максимальные различия в начале цветения составляют также 6 дней. Период цветения ели несколько больше: $10-11$ дней. Различия в начале цветения широколиственных пород (дуб) в разных местах республики достигают 14 дней.

Многочисленные исследования (Stix, 1976 и др.) показывают, что единичные зерна пыльцы березы, сосны, ели, ольхи встречаются в атмосфере круглогодично. При интерпретации спорово-пыльцевых спектров, где отдельные образцы охватывают временной интервал в десятки и сотни лет, присутствие дальнезаносных пыльцевых зерен отдельных пород из-за сильного перемешивания не имеет сушественного значения. Но в то же время, естественно, надо учитывать массовый привнос дальнезаносной пыльцы. В таблице приведены данные максимальной продолжительности периода цветения отдельных видов деревьев на территории Эстон-

Максимальная длительность периода цветения $(\boldsymbol{A})$ и интервал времени $(\boldsymbol{B})$ привноса пыльцы за 1982-1983 гг., дни

\begin{tabular}{l|r|r}
\hline \multicolumn{1}{r|}{ Род дерева } & $A$ & E \\
\hline Сосна & 7 & 13 \\
Береза & 6 & 21 \\
Ель & 11 & 21 \\
Лещина & 10 & 7 \\
Ива & 4 & 8
\end{tabular}
ской ССР и интервала времени, за который скапливалось до $90 \%$ сезонно-привнесенной пыльцы.

Полученные нами данные показывают, что значительное количество пыльцы сосны, березы и ели переносится с больших расстояний: массовое появление пыльцы в любом пункте наблюдения начинается до начала цветения этих растений на территории республики и продолжается дольше цветения. При оценке доли привносимой пыльцы следует учитывать влияние местного рельефа и движения воздушных масс, из-за чего абсолютные количества пыльцевых зерен березы и сосны,
осаждающихся на единицу площади, колеблются в больших пределах.

Появление пыльцы остальных растений лучше подтверждается и фенологическими данными. Исключением являются пункты отбора, находящиеся вблизи моря, например, Пярну, где в атмосфере доля цы граба, современный ареал которого в настоящее время находится в Средней Европе.

На открытом поле (Тоома) динамика появления пыльцы различных древесных пород весьма сходная и мало зависит от характера
почвенного покрова. Зато в местности, где нарушается движение воздушных масс, уже на незначительных расстояниях количественные характеристики распределения пыльцы различаются. Выявленные результаты показывают, что при интерпретации спорово-пыльцевых спектров озерно-болотных отложений необходимо учитывать изменения 
физико-географических условий ландшафта и динамики пространственного развития болот. В практических исследованиях очень важно то обстоятельство, что при большей открытости местности увеличивается доля дальнезаносной пыльцы и что, как правило, при развитии болот (в зарастании озер, при переходе низинных болот в верховые) увеличивается доля пыльцы местной и ультралокальной растительности,

\section{ЛИТЕРА Т У А}

Губанкова С. T. Изучение пыльцы в воздухе Москвы. - В кн.: Палинология в медищине. М., 1973, 23-28.

Палинология в медицине. Труды III Международной палинологической конференции, M., 1973.

Сурова T. Г. Субрецентные спорово-пыльцевые спектры ледниковых районов Шпицбергена. - В кн.: Материалы гляциологических исследований. Хроника, обсуждения. Вып. 43. М., 1982. 157-160.

Bringfelt, B., Engström, I., Nilsson, S. An Evaluation of Some Models to Predict Airborne Pollen Concentration from Meteorological Conditions in Stockholm, Sweden. - Grana, 1982, 21, 59-64.

Stix, E. Jahreszeitliche Veränderungen des Pollengehaltes der Luft. - Flora, 1976, 165, 389-406.

Thomson, P. Der Einfluss des Bruch- und Auenwaldgürtels auf das Pollendiagramm. Schr. phys.-ökon. Ges., 1937, 69, 283-288.

Ннститут геологии

Академии наук Әстонской ССР

Поступила в редакцию 26/IX 1984

Tiiu KOFF, J-.M. PUNNING

\section{OIETOLMU ATMOSFÄARSE OLEKANDE SEADUSPÄRASUSI}

1982. ja 1983. aasta vegetatsiooniperioodil uuriti Eesti NSV territooriumil mitmes vaatlusjaamas sadeneva õietolmu koostist. Saadud andmed näitavad, et enamiku puude ōietolm ilmub atmosfääri enne vastava puuliigi õitsemise algust. Eriti suured erinevused õietolmu massilise sissekande ja öitsemise alguse vahel on männi ja kase puhul, mis viitab nende puude õietolmu kaugsissekandele. Nigula soomassiivil tehtud uuringud näitavad, et sôltuvalt maastiku omapärast võivad õietolmuspektrid ka väikestel kaugustel suuresti erineda. Seega on soo- ja järvesetete õietolmudiagrammide interpretatșioonil vajalik arvestada selle ala maastiku arengutingimusi.

\section{Tiiu KOFF, J.-M. PUNNING}

\section{REGULARITIES OF THE ATMOSPHERIC TRANSFER OF POLLEN}

In the vegetation period of 1982 and 1983, research was carried out into the composition of the pollen outfall at several observation stations situated on the territory of the Estonian SSR. The data obtained reveal that the pollen of the majority of trees appears in the atmosphere before the beginning of the flowering of the corresponding tree species. The differences between the mass occurrence of pollen and the beginning of flowering are especially remarkable in the case of pine and birch, indicating that the pollen of those trees is long-distance transported. The investigations carried out on the territory of Nigula Bog show that, depending on the particular nature of landscape, pollen spectra may differ greatly even at rather small distances. Thus, it is inevitable to take into account the conditions of landscape development in the area concerned in interpreting the paludinal and lacustrine diagrams. 